

\section{Panta Rei \\ Revista Digital de Ciencia \\ y Didáctica de la Historia}

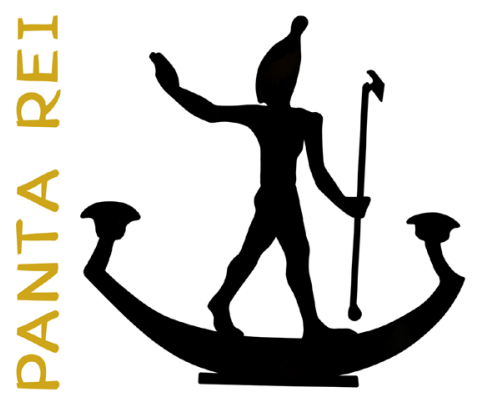

2017

Revista anual

Fecha de inicio: 1995

Revista Panta Rei. pantarei@um.es

Edita:

Centro de Estudios del Próximo Oriente y la

Antigüedad Tardía - CEPOAT

Edificio Universitario Saavedra Fajardo.

Universidad de Murcia

C/ Actor Isidoro Máiquez, 9

30007 - MURCIA - ESPAÑA

Teléfono: (+34) 868883890

cepoat@um.es

Web: www.um.es/cepoat/pantarei

Edición 2017

ISSNe: 2386-8864

ISSN: 1136-2464

Depósito legal: MU-966-1995
cepoAt

UNIVERSIDAD DE MURCIA centro de estudios del próximo oriente y la antigüedad tardia

En Portada: Kaaba durante el Ramadán. Fotografía de Abdullah Shakoor. Creative Commons CCO.

Responsables de los textos: Sus autores.

Responsable de la presente edición: Consejo Editorial Panta Rei. 


\section{CONSEJO DE REDACCIÓN}

\section{Coordinador editorial}

Egea Vivancos, Alejandro

[Didáctica de las Ciencias Sociales, UMU]

\section{Editores}

Botí Hernández, Juan Jesús

[CEPOAT, UMU]

Meseguer Gil, Antonio José

[UNED]

Sáez Giménez, David Omar

[CEPOAT, UMU]

Sánchez Mondéjar, Celso Miguel

[Patrimonio Inteligente]

\section{Secretaria}

Arias Ferrer, Laura

[Didáctica de las Ciencias Sociales, UMU]

\section{Responsable informático}

Martínez García, José Javier

[CEPOAT, UMU]

\section{Traducción y corrección lingüística}

Martínez Martínez, Cristina

[Sociedad Española de Lenguas Modernas]

Albaladejo Albaladejo, Sara

[ISEN, UMU]

\section{CONSEJO ASESOR}

Albero Muñoz, M. ${ }^{a}$ del Mar

[H. ${ }^{a}$ del Arte, UMU]

Chapman, Arthur

[History Education, UCL, Reino Unido]

Cobacho López, Ángel

[Derecho, UMU]

Egea Bruno, Pedro M. ${ }^{a}$

[Historia Contemporánea, UMU]

García Atienzar, Gabriel

[Prehistoria, UA]

González Monfort, Neus

[Didáctica de las Ciencias Sociales, UAB]

Haber Uriarte, María

[Prehistoria, UMU]

Hutson, Scott R.

[Anthropology, UK, EEUU]

Irigoyen López, Antonio

[Historia Moderna, UMU]

Mahony, Simon

[Digital Humanities, UCL, Reino Unido]

Marsilla de Pascual, Francisco Reyes

[Técnicas historiográficas, UMU]

Miralles Maldonado, José Carlos

[Filología Clásica, UMU]

Molina Gómez, José Antonio

[Historia Antigua, UMU]

Noguera Celdrán, José Miguel

[Arqueología, UMU]

Pérez Molina, Miguel Emilio

[Filología Clásica, UMU]

Prados Martínez, Fernando

[Arqueología, UA]

Sánchez Ibáñez, Raquel

[Didáctica de las Ciencias Sociales, UMU]

Sancho Gómez, Miguel Pablo

[Educación, UCAM]

Vilar García, María José

[Historia Contemporánea, UMU]

Zamora López, José Ángel

[Próximo Oriente Antiguo, CCHS-CSIC] 

Artículos

Entre el mito y la historia: el Éxodo de los israelitas desde Egipto a Canaán.

David Villar Vegas.

El Cerro de la Ermita de La Encarnación (Caravaca de la Cruz, Murcia): santuario y territorio en el mundo ibérico del Sureste peninsular.

Leticia López-Mondéjar.

Estelas discoideas y mundo funerario en la Asturias antigua.

Narciso Santos Yanguas......

Filosofía y paganismo en las postrimerías del Imperio Romano de Occidente. El caso del cónsul Mesio Febo Severo.

Rafael González Fernández y Miguel Pablo Sancho Gómez.

Dinámicas identitarias en el Mundo Actual: la religión como identidad frente al otro.

Rafael Ruiz Andrés y Francisco Javier Fernández Vallina.

El patrimonio fenicio-púnico. Claves para su socialización, puesta en valor y uso didáctico.

Helena Jiménez Vialás.

¿Cómo se enseña la llustración en $22^{\circ}$ de Bachillerato? Un análisis de los libros de texto, sus contenidos y la cuestión de género.

Helena Rausell Guillot..... 109

The Role of Local History in Elementary and Secondary Schools in Slovenia: An Evaluation of the Centre for School and Outdoor Education.

Danijela Trškan

Reseñas

Richardson, S. y Garfinkle, S. (eds.) (2016). Scholarship and Inquiry in the Ancient Near East (=Journal of Ancient Near Eastern History special issue, vol. 2/2, 2015) Berlin: de Gruyter. 179 págs.

Juan Álvarez García.

Guldi, J. y Armitage, D. (2016). Manifiesto por la Historia (traducción de Galmarini, M. A. The History Manifesto, 2014). Madrid: Editorial Alianza. 292 págs.

Juan Jesús Botí Hernández y David Omar Sáez Giménez.....

Normas de publicación/Publishing rules 



\title{
Entre el mito y la historia: el Éxodo de los israelitas desde Egipto a Canaán ${ }^{1}$
}

\author{
Between the myth and the history: Israelite's Exodus from Egypt to Canaan
}

\author{
David Villar Vegas ${ }^{2}$ \\ Universidad Complutense de Madrid
}

Recibido: 24/05/2016

Aceptado: 29/01/2017

Para citar este artículo: Villar Vegas, D. (2017). Entre el mito y la historia: el Éxodo de los israelitas desde Egipto a Canaán. Panta Rei. Revista Digital de Ciencia y Didáctica de la Historia, 9-21.

ISSNe: $2386-8864$

DOI: $10.6018 /$ pantarei/2017/1

\section{Resumen}

El presente ensayo parte de la premisa temática de que para realizar una adecuada exposición sobre el Éxodo de los israelitas desde Egipto a Canaán es imprescindible contar con las aportaciones de los hallazgos arqueológicos y de las fuentes literarias, tanto de la Biblia como fuera de ella, y con el mayor número de investigaciones que los especialistas de esta materia hayan realizado.

Se utiliza como perspectiva teórico-metodológica un enfoque crítico que lleva a presentar, en primer lugar, lo aportado por cada una de las fuentes y lo sostenido por los diversos enfoques, para después realizar una contrastación de todo ello con el objetivo de que lo sostenido en cada uno de los temas analizados tenga un fuerte apoyo teórico y empírico.

\section{Palabras clave}

Arqueología, Historia de Oriente Medio, Fuentes bíblicas, Viajes, Judíos.

\section{Abstract}

This essay focuses on the thematic premise which realizes a suitable exhibition of the Israelite's Exodus from Egypt. It is essential to rely on the contributions of the archaeological findings, the literary sources and the majority of the Bible with the most number of research studies conducted by the specialists of this matter.

There is a theoretical - methodological perspective and a critical approach that leads to presenting, first, the contribution for each of the sources and the support for the diverse approaches. Later, it will focus on a contrast of all of this with the aim that the support for each of the analyzed topics has a strong theoretical and empirical support.

1 Este trabajo ha sido realizado gracias al programa de Ayudas para la Formación de Profesorado Universitario (FPU) del Ministerio de Educación, Cultura y Deporte.

2 Para contactar con el autor: David Villar Vegas. Universidad Complutense de Madrid. dvillar@ucm.es. 


\section{Keywords}

Archaeology, Middle Eastern History, Biblical Literature, Travel, Jews.

\section{Introducción}

La arqueología bíblica es la rama de la arqueología que se ha dedicado al estudio y a la investigación de los restos materiales que están relacionados, tanto directa como indirectamente, con el testimonio bíblico. Desde su momento fundacional, en 1865, cuando se crea gracias al patrocinio de la reina Victoria de Inglaterra la Fundación para la Exploración de Palestina (Palestine Exploration Fund), esta disciplina ha pasado por diversas etapas en las que el paradigma que ha caracterizado la forma de acceso al objeto de estudio - la historia y la religión de Israel- ha sido diferente.

En un primer momento hasta mediados del siglo XX, la mayoría de las investigaciones arqueológicas que se llevaron a cabo estuvieron motivadas por su importancia para la interpretación delAntiguo Testamento, por lo que las publicaciones que se realizaron hicieron dialogar sus resultados con los relatos bíblicos. Esto se debió a que los autores de estas obras, en su mayoría también dirigentes de las campañas arqueológicas - como es el caso de William Foxwell Albright-, habían recibido una formación clerical o teológica y estaban convencidos por su fe de que la promesa de Dios a los patriarcas era real y que no había ninguna razón para dudar de la historicidad del Génesis (Finkelstein y Silberman, 2003).

En esta línea aparecieron en 1957 Biblical Archeology de George Ernest Wright - cuya edición más reciente y traducida al español en la Editorial Cristiandad hemos utilizado en este trabajo (Wright, 2002)- y en 1960 A History of Israel de John Bright, las cuales pese a estar en consonancia con la forma de estudio dominante en la época no recibieron la aceptación de toda la comunidad científica. Teólogos protestantes como el alemán Albrecht Alt y estudiosos de la Biblia como el también alemán Martin Noth y el estadounidense George E. Mendenhall criticaron el enfoque adoptado por estos autores e interpretaron de otro modo las mismas memorias de excavación, indicando la existencia de diferencias entre lo que éstas aportaban y lo narrado en el testimonio bíblico - lo cual desarrollaron en sus publicaciones, por ejemplo en Geschichte Israels de 1950 de Martin Noth.

A pesar de que las críticas de estos autores tuvieron un notable seguimiento en el momento en el que fueron realizadas, no sería hasta los años 70 y 80 del siglo pasado cuando hubo un cambio de paradigma en la forma de acceso al estudio de la historia de Israel, caracterizado por el acceso crítico al testimonio bíblico - considerando que lo que en él se contiene puede aportar muy poco para elaborar una verdadera historia de Israel - y ejemplificado en obras como The Historicity of the Patriarchal Narratives de Thomas L. Thompson (1974), Abraham in History and Tradition de John Van Seters (1975) y A History of Israel de Jan Alberto Soggin (1985). El cambio se produjo principalmente porque cada vez era más difícil buscar una correspondencia precisa entre los resultados de las sucesivas campañas de excavación y los detalles contados en los relatos bíblicos.

En estas circunstancias se constituyó a mediados de la década de los 80 , tras la publicación en 1985 de la obra del danés Niels Peter Lemche titulada Early Israel: Anthropological and Historical Studies on the Israelite Society Before the Monarchy, una línea independiente o nueva metodología en la investigación acerca del estudio de Israel conocida como minimalismo bíblico, en la que hoy en día se pueden encuadrar a especialistas de la talla de Mario Liverani o de Thomas L. Thompson aunque ellos a veces no acepten esta denominación y puedan, aún aceptándola, no considerar que formen parte de este grupo. Si bien no se trate de un grupo monolítico ni su percepción de la historia sea uniforme, sí que se pueden establecer una serie de características generalmente comunes en todos ellos. Entre todas ellas la más significativa es la de prescindir de lo que cuenta la Biblia en la interpretación de nuevos hallazgos, ya que afirman que los relatos que en ella se contienen sólo 
cumplen la función de soporte a las concepciones ideológicas de los autores.

Como reacción a los dictados de esta línea o metodología se constituyó su opuesta, conocida bajo el nombre de maximalismo bíblico - el cual tampoco es aceptado por todos los autores y caracterizada por la asepsia del texto bíblico como fuente plenamente fiable en sí mismo, no solo aceptando los hechos verificables sino también aquellos que no se puedan demostrar que son falsos. Esta paráfrasis postracionalista de los relatos bíblicos, cuya obra más representativa es la publicada en 2003 por lan Provan y otros, titulada A Biblical History of Israel, presenta los hechos ajustándose al orden de los episodios bíblicos: patriarcas, asentamiento-conquista de la Tierra Prometida, monarquía unida de David y Salomón, reinos de Israel y Judá y época del exilio a Babilonia.

En una línea distinta a las dos anteriores se sitúa la adoptada por Rainer Albertz en su Historia de la religión de Israel en el tiempo del Antiguo Testamento (1999) y por Paolo Sacchi en Historia del judaísmo en la época del Segundo Templo : Israel entre los siglos VI a. C. y I d. C. (2004). Frente al fundamentalismo no bíblico y bíblico del minimalismo y del maximalismo bíblico este otro enfoque se caracteriza por un acercamiento a la religión desde la historia social, muy pegada a los datos arqueológicos, con un exigente tratamiento crítico de los textos bíblicos (Carbajosa, González y Varo, 2013).

A pesar de la existencia de tres formas distintas de investigar la historia y la religión de Israel, a grandes rasgos, casi todos los estudios relevantes sobre la historia y la religión de este pueblo bíblico desde los años 90 del pasado siglo hasta la actualidad se sitúan sólo dentro de una de ellas, de la línea denominada minimalista. No obstante, en este trabajo impera la concepción de que el dominio de este enfoque no es ni mucho menos una ganancia ya que desde él se renuncia la mayoría de las veces a una información, la de la Biblia, que cuando está bien contrastada es de mucha ayuda para conocer con mayor profundidad lo sucedido en momentos de la historia de gran importancia.

Es por ello que la línea que se sigue en este artículo, que tiene por objetivo determinar si se produjo alguna vez el acontecimiento fundacional de la historia y la religión de Israel, el Éxodo, es la adoptada en las obras anteriormente mencionadas de Rainer Albertz (1999) y Paolo Sacchi (2004), en las cuales se combinan las aportaciones de los datos arqueológicos y las de la Biblia que están adecuadamente contrastadas y analizadas.

El motivo por el cual se ha elegido este tema tiene que ver con su importancia, la cual se demuestra cuando se contempla que los libros del Éxodo, el, los Números y el Deuteronomio cuatro quintas partes de las escrituras fundamentales de Israel - están dedicados a él. No obstante, dicha relevancia no debe hacer pensar que la fecha de composición de los relatos que narran este episodio se sitúa en la misma época a la que hacen referencia, el siglo XIII a. C.

El análisis del testimonio bíblico permite visualizar que los relatos que narran la historia de la liberación de los israelitas de la servidumbre en Egipto son resultado de un habilidoso trenzado de las cuatro fuentes que componen la Biblia: Yahvista (J), Elohísta (E), Deuteronomista (D) y Sacerdotal $(\mathrm{P})^{3}$; todas ellas elaboradas en una época posterior al siglo XIII a. C. - siglo IX-VIII, VIII, VII y VI-V a. C., respectivamente.

Por ello es tan interesante la realización de este trabajo, tanto por el tema que aborda, la experiencia fundacional de Israel, como por la metodología que en él se sigue para llevarlo a cabo, en la que se tiene en cuenta la Biblia pero - siendo conscientes de su tardía composición - se cuenta con el apoyo de otras fuentes.

En consonancia con estos planteamientos y con el propósito de satisfacer el objetivo de esta investigación y que el mismo sea comprendido perfectamente por el lector, se ha estructurado el ensayo en cinco partes bien diferenciadas. En la primera de ellas, se analizará el grado de conocimiento del Éxodo en el Antiguo Israel; en la segunda se abordará la presencia de los israelitas

3 A modo de ejemplo de este "habilidoso trenzado" cabe destacar que los dos primeros capítulos del libro del Éxodo son una compilación de tres de estas fuentes, a saber: J, E y P (Baden, 2012, p. 144). 
en Egipto; en la tercera, los acontecimientos relacionados con su posible entrada y la situación en la que éstos allí se encontraban; y, en la cuarta y última, los elementos propiamente relacionados con el Éxodo de los israelitas desde Egipto a Canaán para ver si en realidad éste se produjo, a saber: su cronología, sus causas, sus participantes y ver si es posible describir el itinerario que siguieron hasta llegar a Canaán.

Una vez se haya concluido el desarrollo de estas partes, en un apartado de consideraciones finales, se realizarán las objeciones pertinentes al tratamiento de los acontecimientos y de las fuentes por los distintos autores y se tratarán de definir las principales líneas de trabajo y de investigación que se deben seguir en el futuro.

\section{El relato del Éxodo en el Antiguo Israel}

La premisa con la que ha partido este ensayo, debido al consenso existente en el ámbito académico (Na'aman, 2011), ha sido la de aceptar que el relato del Éxodo es el acontecimiento señero de la fe y de la historia de Israel. Sin embargo, ¿desde cuándo los israelitas tuvieron conocimiento de esta experiencia de opresión y liberación?

Los estudiosos coinciden en señalar que la tradición del Éxodo fue aceptada primeramente en el reino de Israel debido a que las líneas generales del relato eran conocidas en las profecías de los profetas Amós y Oseas del siglo VIII a. C. y en algunos salmos tempranos de origen norteño ( $P s$ 77, 80 y 81). No obstante, el que contenidos de estos relatos fueran tan dominantes en la historiografía judaíta escrita en el siglo VII a. C., incluyendo la celebración de la Pascua en el año dieciocho del reinado de Josías de Judá - 621 a. C.- (2Re 23, 21-23), les hace considerar que su conocimiento también se pudo dar en el reino meridional antes del siglo VII a. C., lo cual se apoya en el contenido de la Canción del Mar (Ex 15, 1-17) y en el de algunos Salmos sureños (Ps 78, 114).

El conocimiento del Éxodo durante la existencia de los reinos de Israel y Judá está también atestiguado por las múltiples referencias que indican que existía una transmisión de padres a hijos del recuerdo de sus relaciones directas con los grupos que habían construido o reconstruido las dos ciudades mencionadas en la Biblia - Pitón y Pi-Ramsés- del delta del Nilo (Soggin, 1985).

Estos elementos son los que llevan a afirmar que las primeras obras de la historia de Israel probablemente abrieran con la historia del Éxodo y no con los relatos de los patriarcas (Na'aman, 2011). El lugar excepcional de la tradición en estas primeras obras y en la conciencia histórica del reino de Israel y de Judá es un punto a favor de la cuestión de la autenticidad de la memoria histórica reflejada en la historia del Éxodo que será tenido en cuenta en este trabajo.

\section{La presencia de los israelitas en Egipto en el siglo XIII a. C.}

Una vez aclarada la cuestión del conocimiento del relato del Éxodo en el Antiguo Israel es momento ahora de abordar el tema de la presencia de los israelitas en Egipto, para lo cual, siguiendo la estructura planteada en la introducción y que a partir de aquí se imitará en los siguientes puntos, se presentarán en primer lugar las fuentes disponibles, muy limitadas para la reconstrucción de este período.

\subsection{Fuentes bíblicas y extrabíblicas que informan de la presencia de los israelitas en Egipto}

Las fuentes de las cuales los especialistas se han servido para confirmar la presencia israelita en territorio egipcio se pueden dividir en dos grupos: las de origen egipcio y las contenidas en la Biblia. Dentro del primero estarían los papiros de Leiden 348 y 349 que mencionan a unas gentes - $p r^{4}$ - transportando piedra para una construcción en la región de Menfis (De Vaux, 1975), la estela

4 En la estela dice: "Provéase de grano [...] a los pr que acarrean las piedras para edificar la espléndida Pylón 
del faraón Sethnacht - 1190-1187 a. C.-, en la cual se habla de la expulsión de unos asiáticos que habían aprovechado la influencia de ciertos grupos militares para hacerse con el poder ${ }^{5}$ y las aportadas por el egiptólogo Donald Redford de la dinastía Saíta o XXVI en las cuales se menciona la realización de proyectos constructivos en el delta del Nilo por extranjeros (Finkelstein y Silberman, 2003).

Respecto a las contenidas en la Biblia estarían los nombres egipcios que para algunos confirman la presencia en este lugar del grupo levítico del que formaba parte Moisés (De Vaux, 1975), los detalles de las diez plagas - que se desarrollarán posteriormente- que hacen referencia a fenómenos que aún hoy en día azotan a Egipto (Wright, 2002) y los testimonios del relato del Éxodo que mencionan la construcción por parte de los israelitas de dos ciudades, Pitón y Pi-Ramsés, de cuya existencia es imposible dudar (De Vaux, 1975).

\subsection{Tratamiento de las fuentes}

El tratamiento de las fuentes disponibles para confirmar la presencia israelita en Egipto ha sido muy heterogéneo por parte de los distintos autores y lo sigue siendo hoy en día. No obstante, sí que parece existir un consenso en la actualidad en catalogar como inservibles para probar la presencia israelita tanto el motivo de los nombres egipcios (Soggin, 1985) como los elementos descritos en el relato de las diez plagas ( $\mathrm{Na}^{\prime}$ aman, 2011).

A partir de aquí se puede hablar de la existencia, a grandes rasgos, de dos formas de interpretación y tratamiento de las fuentes anteriores. La primera de ellas, en la que se podría situar a George Ernest Wright, Rainer Albertz, Francisco Varo y Roland de Vaux, considera que éstas sí que permiten hablar de la existencia de un grupo de israelitas en el siglo XIII a. C. en Egipto. Esto es así, principalmente, porque admiten como posible que las gentes mencionadas en los papiros de Leiden 348 y 349 y en la estela del faraón Sethnacht hagan referencia a los integrantes del grupo del Éxodo. Además, consideran que las construcciones que se mencionan en la Biblia en las ciudades de Pitón - Tell er-Retabeh en la actualidad- y Pi-Ramsés - antes Tanis, capital de los hicsos - se pudieron dar perfectamente en el siglo XIII a. C. ya que la primera de ellas no tuvo construcciones regias de monarcas anteriores a Ramsés II (Wright, 2002) y la segunda estuvo abandonada desde 1570 a. C. hasta la subida al trono de este faraón, desapareciendo de nuevo su nombre de los textos egipcios antes del final de la dinastía XX (De Vaux, 1975).

En una posición diferente estarían autores como Juan Alberto Soggin, Israel Finkelstein, Mario Liverani y Nadav $\mathrm{Na}$ 'aman, los cuales afirman que no existe ningún testimonio fiable que permita aceptar la presencia de israelitas en Egipto en el siglo XIII a. C. El motivo principal de esta afirmación se basa en que, a diferencia de los anteriores, no consideran que las gentes mencionadas en los papiros de Leiden 348 y 349 y en la estela del faraón Sethnacht se puedan relacionar con seguridad con los israelitas. No obstante a partir de aquí surgen las diferencias entre ellos, mientras que para Soggin y Na'aman las fuentes no permiten afirmar la existencia de una comunidad israelita en un tiempo concreto (Soggin, 1985), Mario Liverani e Israel Finkelstein, siguiendo las tesis de Redford, afirman que sólo éstas permiten aceptar la existencia de una comunidad israelita en Egipto en el siglo VII a. C., bajo el gobierno de la dinastía Saíta (Finkelstein y Silberman, 2003).

\subsection{Hipótesis y hechos comprobados sobre la presencia de los israelitas en Egipto en el siglo XIII a. C.: la relación entre los habiru y los israelitas}

Una vez analizadas las fuentes anteriores y su tratamiento por parte de distintos autores, se puede afirmar con seguridad que en el período al que alude la Biblia, el siglo XIII a. C., sí

de [...] de Ramsés Miammun" Traducción de K. Galling en Texte zur Geschichte Israels 2 (1968) recogida en (Albertz, 1999, p. 92).

5 Traducción de la estela en M. Gorg Ausweisung (1978) recogida en (Albertz, 1999, p. 91).

Panta Rei (2017), 9 - 21 
que se produjeron construcciones en las ciudades de Pitón y de Pi-Ramsés. No obstante, el que estas construcciones las realizaran los israelitas, y por lo tanto se confirme su presencia en aquel momento, es algo que no se puede afirmar con la misma seguridad ya que depende de que los habiru citados en las fuentes egipcias correspondan a los israelitas del Éxodo.

Actualmente existe un consenso en admitir que el empleo de esta palabra, extendido a lo largo del segundo milenio a. C. por todo Oriente Próximo, da a entender que, más que significar un grupo étnico específico, tenía un significado socioeconómico, traduciéndose por "apátridas" o "desplazados". A partir de aquí están los que consideran - Mario Liverani, Juan Alberto Soggin e Israel Finkelstein entre otros - que pese a que no se pueda descartar del todo alguna vinculación, las probabilidades de que ésta exista son muy pequeñas y los que sí que la ven como posible, cuya opinión se comparte en este trabajo por los siguientes motivos.

En primer lugar porque se apoya la concepción de que la relación etimológica del término hapiru-habiru de los textos antiguos del Próximo Oriente con el término bíblico ibri puede establecerse como razonablemente segura. Este término, ibri, alude a los hebreos, los cuales eran parte de la sociedad israelita según ilustran varios textos de la Biblia como en $2 \mathrm{Sa} 20,14$. En segundo lugar, porque se aprecian similitudes entre las bandas habiru del segundo milenio a. C. y las de hebreos integrados en la primitiva sociedad israelita, como la de David (Na'aman, 1984), cuya existencia se ha podido comprobar (Finkelstein y Silberman, 2003). En tercer lugar, respecto a la evolución de un término de carácter socioeconómico como es el de habiru a uno de carácter étnico como es el de ibri, se puede aceptar que este cambio se produjo a finales del primer milenio a. C., cuando el término habiru desapareció de la escena histórica de Asia occidental a partir de la formación de diversos estados y aparecieron otros de carácter étnico que se utilizaron para denominar a los propios habiru de cada territorio, como ibri (Na'aman, 1984).

Por todo ello - con la conciencia de que no es una cuestión ni mucho menos cerrada ya que en la actualidad se sigue discutiendo sobre el tema, lo cual refleja la publicación de varias monografías sobre el significado del término ibri con ideas opuestas a la de este trabajo (entre ellas estarían Loretz, 1984, y Durand, 2004-2005)- se considera como posible que los habiru de las fuentes egipcias hagan alusión a los israelitas y que aunque su presencia en el siglo XIII a. C. en Egipto no se pueda afirmar con total seguridad, existen una serie de indicios que permiten plantearla como probable. En el siguiente apartado, se analizará la forma en la que estos israelitas pudieron haber llegado a Egipto y las condiciones en las que vivían.

\section{Origen y características de los israelitas asentados en Egipto}

\subsection{La entrada}

A lo largo de la historia se han propuesto diversas alternativas para explicar el origen de una comunidad israelita en el siglo XIII a. C. en Egipto. Una de ellas es la que acepta la tesis sostenida en la Biblia de que el origen de esta presencia se debe situar a principios del segundo milenio a. C. con la entrada de José ( $G e$ 37, 36; Ge 39) y su familia. Estos autores aluden que la presencia de José y su posición está plenamente atestiguada en los relieves e inscripciones egipcias que hablan de gobernantes asiáticos, mientras que el momento de su entrada lo corroboran aquellas que aluden a la llegada de familias nómadas, como la de Abisar, que penetraron en Egipto en torno al año 1900 a. C. Sostienen que si no se tienen inscripciones que hagan referencia a la entrada de José y su familia no se debe a que ésta no se haya producido sino a que las inscripciones no se han conservado (Wright, 2002).

Otra hipótesis es la que afirma que se debe vincular el origen y la llegada de los israelitas a Egipto con la de los hicsos a mediados del siglo XVII a. C., la cual supuso el final del Imperio Medio de Egipto y el inicio del Segundo Período Intermedio. Esta vinculación se basa, principalmente, en un pasaje de la Biblia, (Nu 13, 22), en el cual se establece la fundación de Hebrón conforme a la de Tanis, capital de los hicsos en el Delta: "Hebrón fue edificada siete años antes que Soán (Tanis) en 
Egipto". Afirman que con este pasaje es lógico deducir que debió de haber hebreos relacionados con la actividad de los hicsos y que se hallaban en Egipto cuando tuvo lugar la fundación de Tanis (De Vaux, 1975).

En la actualidad existe un consenso entre los especialistas en no dar como válidas ambas hipótesis, lo cual, desde el punto de vista de este trabajo, es acertado. Respecto a la historia de José cabe destacar que ésta no es recogida ni siquiera en las dos tradiciones de la Biblia que hablan sobre la llegada de los israelitas a Egipto, ya que únicamente está presente en las dos de Génesis y en la del libro del Éxodo y no en la de Deuteronomio 26, 5 y Libro de Josué 24, 4. Además, las características del relato demuestran que es una construcción tardía y una unidad literaria autosuficiente que no presupone ni lo que la precede ni lo que viene a continuación (Soggin, 1985).

Respecto a la llegada de los israelitas en el siglo XVII a. C. con los hicsos no se descarta la vinculación que pueda existir entre ambas poblaciones sino la llegada repentina de una nueva población a Egipto desde Canaán en este momento. Siguiendo la tesis de Albrecht Alt, el origen de los hicsos se puede relacionar más bien con los núcleos semitas y hurritas instalados ya desde tiempo atrás en el delta oriental del Nilo que, a finales del primer cuarto del segundo milenio a. C., se hicieron con el poder aprovechando los desórdenes del Segundo Período Intermedio (Soggin, 1985).

Esta evolución prolongada y progresiva de la presencia cananea y la toma de poder pacífica en el Delta encuentra su apoyo en los testimonios arqueológicos de Tell ed-Daba - yacimiento situado al este del delta que corresponde con la antigua capital de los hicsos. Éstos ilustran un aumento gradual de la influencia cananea en los estilos de cerámica, arquitectura y tumbas a partir, aproximadamente, del 1800 a. C., que, al cabo de ciento cincuenta años en tiempos de la Dinastía XV terminó por ser la característica del yacimiento (Finkelstein, 2003).

En conclusión, las fuentes disponibles no permiten establecer ni cómo ni cuándo llegaron los integrantes del grupo del Éxodo a Egipto. Únicamente, tal y como se ha apuntado en el apartado anterior, se puede afirmar que su presencia allí se pudo dar en el siglo XIII a. C. Partiendo de esto, se profundizará a continuación en las características de esta presencia y en las condiciones en las que vivían en aquel momento.

\subsection{Condiciones de vida: Esclavos o trabajadores, nómadas o sedentarios}

La imagen bíblica de los integrantes del grupo del Éxodo es uno de los innumerables ejemplos que se dan en este libro sagrado, y en otros muchos, de la integración inconsciente por parte de los autores, al describir acontecimientos que los precedieron por muchos años, de datos que reflejan la realidad de su propio tiempo.

La presencia de los israelitas como una comunidad grande, con su propio liderazgo y autonomía, viviendo segregados, no se ajusta a la realidad de Egipto en la época del Imperio Nuevo, sino que refleja la del período Saíta en adelante - siglo VII a. C. Asimismo, los expertos han señalado que el trabajo en régimen de esclavitud refleja mejor la realidad de Asia Occidental en los siglos octavo y séptimo antes de Cristo, en particular la de la organización de las operaciones de construcción a gran escala en el Imperio Asirio (Na'aman, 2011).

Por otra parte, tampoco se cree que la orden dada por el faraón a las comadronas de matar a los varones recién nacidos para detener drásticamente el crecimiento del pueblo se corresponda con la realidad, debido a que esto condenaría a la población del grupo del Éxodo masculina al envejecimiento y a la extinción, fracasando una de las finalidades de los trabajos en los que participaban, la productividad (Soggin, 1985).

Entonces, si los israelitas asentados en Egipto no estaban bajo el régimen de esclavitud descrito en la Biblia, ¿por qué estaban trabajando en la construcción de las ciudades de Pitón y Pi-Ramsés?, ¿qué era lo que les obligaba?, ¿cómo vivían sino era en una comunidad grande y segregados de la población egipcia? 
La propuesta más acertada para responder a estas preguntas es la planteada por Rainer Albertz y Francisco Varo. Según ellos los integrantes del grupo del Éxodo fueron un grupo de prisioneros de guerra que se integraron o unieron en el campo de trabajo por el culto a YHWH - lo cual se desarrollará en los siguientes apartados. Sobre su forma de vida descartan - lo cual es compartido en este trabajo - que fueran nómadas y sostienen que estaban familiarizados con la vida en Egipto. Encuentran como apoyo de esta afirmación el que en los relatos tradicionales se refleje que no tenían experiencias recientes de vida nómada, ya que las añoranzas que en ellos se citan a los pepinos, sandías, cebollas, etc., no son propias de ello sino de gentes que han estado viviendo en zonas de huertas y campos de cultivo desde hace bastante tiempo (Carbajosa et al., 2013).

Por tanto, después de haber constatado que es posible afirmar la presencia del grupo del Éxodo en Egipto en el siglo XIII a. C., quiénes eran pero no de donde provenían y la forma de vida que llevaban, es momento ahora de que en el siguiente apartado se analice la experiencia de liberación que según la Biblia estas gentes tuvieron cuando salieron de Egipto, el Éxodo. Para ello, en primer lugar, se intentará establecer la fecha en la que se produjo este episodio - teniendo en cuenta la información de estos apartados - y determinar las causas que lo provocaron, en segundo lugar, ver si se puede comprobar la existencia de su más ilustre participante, Moisés; en tercer lugar, la prueba con más solidez para decir que fue posible la llegada de un grupo de israelitas a Canaán, el origen de la adoración a YHWH; y, en último lugar, si se pueden localizar los principales elementos descritos en el itinerario de Egipto a Canaán y si existe algún testimonio que los relacione con el grupo del Éxodo.

\section{El Éxodo de los israelitas desde Egipto a Canaán}

\section{1. ¿Cuándo y por qué se produjo el Éxodo?}

La Biblia establece que la salida de Egipto se produjo bajo el gobierno de un nuevo faraón que no había conocido a José $(E x 1,8)$ gracias a la ayuda de $\mathrm{YHWH}$, dios del grupo del Éxodo, que ayudó a su pueblo debido a las penurias que allí estaba pasando. Ésta tuvo lugar, concretamente, cuando el faraón fue testigo del horrible tributo de la décima plaga que YHWH mandó a Egipto para liberar a su pueblo, la de la muerte de los primogénitos - incluido el suyo -, tras la cual cedió por fin y pidió a los israelitas que se marcharan junto con sus rebaños de ovejas y demás ganado (Finkelstein y Silberman, 2003). Sin embargo, ¿es así como ocurrió?

En este trabajo se ha comprobado que es posible plantear la presencia de lo que más tarde serían los israelitas en el siglo XIII a. C. como un grupo de prisioneros que llevaban una vida sedentaria y eran sometidos a trabajos forzados en la construcción de las ciudades y templos. No obstante, ¿esto sirve para determinar la fecha de una posible salida de Egipto y sus causas?, ¿existen otras fuentes que puedan ayudar para confirmar lo dicho por la Biblia?

En el registro arqueológico de la península del Sinaí nunca se ha identificado ni un solo lugar de acampada o signo de ocupación a lo largo del siglo XIII a. C. Por tanto, las únicas fuentes disponibles para establecer una fecha del Éxodo son las que han servido para confirmar la presencia israelita en Canaán y una nueva, la estela del faraón Merneptah - 1207 a. C. -, hijo de Ramsés II, que recoge la mención más temprana de Israel en un texto extrabíblico (Finkelstein, 2003).

La inscripción menciona la campaña llevada a cabo por este faraón en torno al año 1230 a. C. contra Canaán, en cuyo transcurso fue diezmado un pueblo denominado Israel, de lo cual se vanagloriaba el propio faraón diciendo que "Israel está baldío, y no tenía simiente" último se tratase de una vana presunción, demostraba que en aquellos tiempos existía en Canaán una entidad conocida por el nombre de Israel, a la cual se han vinculado los asentamientos que

6 Traducción de la estela de K. Galling en Texte zur Geschichte Israels 2 (1968) recogida en (Albertz, 1999, p. 145). 
aparecieron por entonces en las serranías cananeas. Esto se ha utilizado por algunos especialistas para decir que el Éxodo se produjo entre el tercer y último cuarto del siglo XIII a. C., justo antes de que tuviera lugar la campaña llevada a cabo por este faraón (De Vaux, 1975; Carbajosa et al., 2013).

Según el punto de vista sostenido en este trabajo, esta utilización no es del todo correcta ya que el nombre de Israel no tiene por qué guardar necesariamente una relación con el grupo del Éxodo. Si se analiza, se ve que el significado de este nombre (Yisra'el) es "Dios o El reina" o "Que Dios o El se muestre como soberano", lo cual no expresa ninguna relación ni con el grupo del Éxodo ni con el Dios al que adoraban según la Biblia, YHWH. La mención, siguiendo a Albertz (1999), puede aludir perfectamente a un Israel pre-yahvístico que adorara al dios cananeo El.

Por lo tanto, no se tiene por qué retrasar la fecha del Éxodo hasta antes del año $1230 \mathrm{a}$. C. porque la estela de Merneptah no tiene por qué hacer alusión al grupo que sufrió la opresión y posteriormente la experiencia de liberación de Egipto. El Éxodo también se pudo producir justo al final del reinado de Ramsés, pero tampoco se puede descartar, si aparecen más datos que lo confirmen, que pudiera haber tenido lugar a inicios del siglo XII a. C., lo cual puede sugerir la estela del faraón Sethnacht.

Respecto a las causas, las fuentes no permiten plantear con seguridad cuál pudo haber sido el motivo de la salida - o huida - de este grupo de prisioneros de Egipto a Canaán, pudiendo únicamente sugerir que tratasen de encontrar una vida mejor. Por otra parte, aquellos que relacionan la salida con el relato de las diez plagas de Egipto, como hace la Biblia, cometen una equivocación. Si bien pueden verse similitudes, a grandes rasgos, con fenómenos naturales de la región, éstas son más bien una composición literaria que un texto histórico-legendario, lo cual se demuestra cuando se ve que no todas las fuentes de la Biblia presentan un cuadro completo de todas ellas: En J hay sólo siete y en E y P sólo cinco. En definitiva, siguiendo a Roland de Vaux (1975), el relato de las plagas no es una recopilación de antiguas tradiciones que se remontan al recuerdo de acontecimientos del pasado sino una obra concebida en el escritorio.

\subsection{Moisés}

Si hay alguien en los relatos del Éxodo, aparte de YHWH, cuya participación resulte imprescindible, ésta es, sin lugar a dudas, la de Moisés. Este personaje, cuyo nombre deriva de un verbo egipcio que significa engendrar o engendrado (Wright, 2002), fue el que recibió la revelación del nombre del Dios del grupo del Éxodo - YHWH - y el que, con sus consejos y con la ayuda de sus acciones, se puso al frente para guiarlos hasta Canaán (Finkelstein y Silberman, 2003). Sin embargo, no pocos autores han cuestionado tanto su participación como su existencia debido a una serie de razones.

La primera de ellas tiene que ver con que se pueden encontrar paralelos de algún aspecto de su historia, concretamente de su nacimiento y de su muerte, en la de otros monarcas como Sargón de Acad y Ciro II de Persia, respectivamente. La segunda, en que si de verdad su existencia fuese fundamental, como ocurre con Jesús de Nazaret para el cristianismo, su nombre aparecería frecuentemente en la Biblia hebrea, al igual que ocurre en el Nuevo Testamento con Jesús. Sin embargo, en la Biblia hebrea hay muy pocos textos en los que Moisés sea mencionado fuera del Pentateuco. Por estos motivos, estos autores afirman que Moisés únicamente es una figura - en gran medida artificial- de enlace, elaborada en tiempos de la reforma deuteronomista - primer momento en que asumió una figura central en la tradición bíblica -, entre las leyendas patriarcales y el gran tema de la conquista de la Tierra Prometida (Liverani, 2005).

Sin embargo, existen otros testimonios que parecen estar a favor de la existencia de Moisés, como la mención que se hace en el libro del Éxodo de su llegada a Madián, lugar a cuyas mujeres se culpó en tiempos posteriores de haber inducido a la idolatría a los israelitas, por lo cual estas gentes tuvieron la consideración de terribles enemigos. Los autores que se sirven de este testimonio afirman que no parece verosímil que en ese contexto de enemistad entre israelitas y madianitas se inventasen unas escenas como éstas en las que Moisés demuestra una actitud amigable y abierta 
a los madianitas, radicalmente distinta a la que caracterizaría más tarde las relaciones de ambos pueblos (Carbajosa et al., 2013).

Por ello y porque la tradición madianita es ciertamente antigua, sostienen que no hay razón para admitir que la introducción en ella de la figura de Moisés se hiciera de forma secundaria sino que ésta tuvo que tener un fundamento histórico. En este trabajo, aun reconociendo que hay varios elementos en torno a su figura que pudieron añadirse cuando se elaboraron los relatos y que determinar su historicidad con seguridad es hoy en día imposible, se piensa que se debe admitir su existencia como probable ya que, suprimiendo a Moisés, muchos elementos de la religión de Israel se hacen inexplicables (De Vaux, 1975).

\subsection{YHWH, un dios de origen no cananeo}

El acontecimiento más importante de los relatos del Éxodo es la revelación de Moisés a YHWH, acontecida en el monte Horeb o Sinaí y recogida en la Biblia en Éxodo 3, 5-14. Es en este momento cuando YHWH revela su naturaleza y su nombre a Moisés y le encomienda el propósito de volver a Egipto, tras haber sido desterrado de allí por matar a un capataz (Finkelstein, 2003), y liberar al pueblo al que pertenece.

En este ensayo se ha planteado que fue el culto a este dios lo que unió a la masa de trabajadores y prisioneros a formar una comunidad que más adelante sería la que salió de Egipto. No obstante, ¿hay elementos que permitan realizar esta afirmación con seguridad?, ¿qué se sabe acerca de YHWH y los orígenes de su adoración?, ¿realmente ésta se sitúa en el monte Horeb o Sinaí?, y, en este caso, ¿dónde se tendría que situar este lugar?

Con el objetivo de dar respuesta a todas estas preguntas se desarrollará a continuación, brevemente, la llamada hipótesis quenita-madianita, propuesta más aceptada en la actualidad en el ámbito académico para determinar los orígenes de la adoración a YHWH, la cual se tendría que situar como anterior a Moisés y a la existencia de Israel en ciertas tribus de la zona de Hiyaz al noroeste de Arabia - Madián (Day, 2000).

Antes de desarrollar esta propuesta es importante destacar que es de vital importancia su inclusión en este trabajo, porque no sólo ayuda a elaborar el itinerario del Éxodo que se abordará en el siguiente punto o, como es obvio, a determinar los orígenes de la adoración a $\mathrm{YHWH}$, sino que también constituye, debido a la ausencia de solidez de las cuestiones que se han tratado anteriormente, uno de los mayores apoyos a la historicidad del Éxodo al establecer el origen de la adoración a YHWH en un territorio fuera de Canaán y de gran importancia en el relato, Madián.

\section{3.a. La hipótesis quenita-madianita}

Como se ha mencionado anteriormente, la hipótesis quenita madianita sugiere que el nombre de YHWH estaba en uso, antes de Moisés y de la existencia de Israel, entre ciertas tribus semitas en la zona de Hiyaz. La hipótesis se hizo muy popular a comienzos del siglo XX por un trabajo de Karl Budde - Die Religion des Volkes Israel bis zur Verbannung (1899) - y los datos más importantes que parecen sostenerla o corroborarla son los siguientes.

En primer lugar existen una serie de antiguos textos poéticos que atribuyen a $\mathrm{YHWH}$ una vinculación local con esa región (Soggin, 1985), que recibe en ellos diversos nombres, como Sinaí, Se'ir, Campos de Edom, Temán o Monte Farán - Deuteronomio 32, 2, Libro de Josué 5 , 4-5, Salmos 68, 18 - en los que incluso se designa a YHWH, con un epíteto muy antiguo, como el que viene del Sinaí. Deuteronomio 33, 2 "Dijo: ha venido YHWH del Sinaí. Para ellos Seír se ha levantado, ha iluminado desde el norte Parán. Con él las miradas de Cadés, ley de fuego en su diestra para ellos". En ese mismo sentido van las indicaciones que da el Antiguo Testamento sobre la estrecha vinculación de Moisés con los madianitas. En Éxodo 18, 12 que sea Jetro el que invite a los israelitas a ofrecer un sacrificio a YHWH en la montaña sagrada da pie para suponer que los madianitas o los quenitas ya adoraban a $\mathrm{YHWH}$. 
En segundo lugar, estarían una serie de testimonios arqueológicos que también apoyan esta localización. Se dispone de unas catalogaciones egipcias de la época de Amenhotep III - primera mitad del siglo XIV - y de Ramsés II que recogen la mención de "Y-h-w-" en tierras de "S'sw" (Giveon, 1971), es decir, en esa misma región al sur de Palestina. Si YHW y SEÍR son corónimos - nombres de regiones - o etnónimos - nombres de etnias -, la mención de Seír en este contexto invita a concluir que YHW era un lugar próximo de la misma región, los alrededores de la costa norte del Golfo de Aqaba, precisamente la región donde los fragmentos poéticos antes mencionados sitúan el lugar de origen de YHWH. No se puede excluir absolutamente que esta mención esté relacionada con el culto a una divinidad local de idéntico nombre. En otra inscripción, "YHWH de Temán" (Weinfeld, 1984), de Kuntillet Ajrud, que puede datarse en torno al 800 a. C., también se apoya esta localización. La arqueología también ha aportado evidencias sobre la existencia de una civilización en esta zona en el Bronce Final/Edad del Hierro, en contraste con la falta de datos en este período para la península del Sinaí, planteada por otros como posible localización de la montaña sagrada y del origen de YHWH (Day, 2000).

Por otra parte, no cabe pensar que los israelitas de una época posterior localizaran a su Dios en un territorio extranjero, alejado del espacio geográfico de Israel si ello no respondía a un recuerdo mínimamente histórico. Es muy improbable que los israelitas pudieran inventar el origen madianita del dios $\mathrm{YHWH}$, dada la hostilidad que mantuvieron permanentemente en épocas posteriores con ellos (Trebolle, 2008).

Por último, no se puede estar seguro de las características de YHWH antes de que fuera adoptado por el grupo del Éxodo, donde tiene los rasgos de dios guerrero, liberador, de la naturaleza y de la historia. Se puede suponer que fuera una especie de dios de las tormentas o dios de los ejércitos, sin embargo, no se sabe con seguridad. Asimismo, tampoco se puede afirmar si su culto se daba o no junto a otros dioses o si sólo él era adorado.

\subsection{El itinerario del Éxodo}

Después de haber planteado la presencia israelita en el siglo XIII a. C. en Egipto, la forma de vida que llevaban, la fecha en la que pudieron salir de Egipto, la plausible historicidad del personaje que los lideró y la localización del monte donde recibió la revelación, sería momento ahora de, para finalizar este trabajo, describir la posible ruta que el grupo del Éxodo tomó desde que salió de Egipto hasta que llegó a Canaán.

No obstante, lo analizado en los anteriores apartados no permite elaborar un itinerario de tales características - elaborarlo sería ir en contra del espíritu de este ensayo - debido a que no hay evidencias fuera de la Biblia que puedan confirmar todos los pasos y porque no se considera adecuado fiarse de las indicaciones que en el libro sagrado se recogen ya que éstas están llenas de alusiones a distintas épocas (Liverani, 2005), lo cual no permite tener un conocimiento seguro sobre los pasos que el grupo del Éxodo pudo dar.

De este itinerario únicamente se puede decir que salieron de Pi-Ramsés a finales del siglo XIII a. C. o a principios del s. XII a. C., que pudieron cruzar el mar en algún punto cercano al lago Timsah - siguiendo la tesis de Noth (Soggin, 1985) - aunque no se pueda confirmar - y que llegaron a Canaán por algún camino que no fuera el del norte, ya que se sabe de su vigilancia constante en la época y de la existencia de grandes fortalezas como la de Zilu - Thel (Wright, 2002).

Ni siquiera el Código de la Alianza y el Decálogo se pueden atribuir a este itinerario con seguridad ya que, a pesar de que contengan materiales que daten de la segunda mitad del segundo milenio a. $\mathrm{C}^{7}{ }^{7}$, presuponen una profunda teologización del derecho que sólo se produjo a partir de

7 Un ejemplo es el caso (Ex 21, 28-32) del toro que acornea a otro toro, o a una persona libre, o a un esclavo, y que exige la muerte del toro asesino, pero con la responsabilidad de su propietario sólo en caso de que ya anteriormente hubiera sido advertido de la peligrosidad del animal, circunstancia que encontramos a su vez en las leyes de Eshunna y Hammurabi (Liverani, 2005).

Panta Rei (2017), 9 - 21 
finales del siglo VIII a. C. (Albertz, 1999).

\section{Reflexiones finales}

Llegados a este punto y después de haber analizado todos los elementos que se propusieron en la introducción a este ensayo, se puede afirmar que hay más indicios que sugieren la historicidad de los relatos del Éxodo que los que lo desmienten. Y esto no sólo es así por los datos proporcionados por la arqueología o por los documentos extrabíblicos - de carácter científico-, sino, como se ha hecho referencia al comenzar este trabajo, porque negar la historicidad del Éxodo supondría negar la historicidad del impulso decisivo que puso en marcha la historia de la religión israelita. Un impulso que brotó de una experiencia religiosa específica vivida por el grupo del Éxodo en Egipto y, posteriormente, en las regiones desérticas al sur de Palestina.

Sólo esta experiencia explica que la dimensión social que definió la religión yahvista, la cual se constituyó a partir del Éxodo, fuese absolutamente diferente de la religiosidad que describen los relatos patriarcales, la cual guarda relación con la religiosidad familiar de finales del segundo milenio a. C. Por otra parte, si esta tradición no hubiera poseído un gran impulso de liberación social, difícilmente habría podido servir de punto de referencia a episodios posteriores como la rebelión de Jeroboán, y jamás habría llegado a adquirir una configuración literaria.

Los autores que niegan esta historicidad, como Israel Finkelstein, Mario Liverani y Nadav $\mathrm{Na}$ aman cometen una serie de errores cuando abordan esta problemática, aunque como se ha visto no se puedan descartar todas sus aportaciones. El primero de ellos se centra demasiado en la etapa de elaboración y formación de los relatos, lo cual le hace finalmente constreñir todo a ese período, no sólo el Éxodo, sino también otras tradiciones como la de los patriarcas y la de la Monarquía Unificada de David y Salomón. Mario Liverani, por otra parte, se equivoca cuando utiliza las formas verbales del Próximo Oriente para reconstruir el significado de las del hebreo bíblico, reflejado perfectamente en el trabajo de Na'aman (2011), lo cual le lleva a cometer el error de suponer que el testimonio de Oseas 7,11 no alude a un movimiento de personas sino a un cambio de fronteras y control político (Liverani, 2005). El último de ellos, Na'aman, sorprendentemente, comete un error al establecer esa memoria de la liberación en Canaán y negar la estancia en Egipto, de lo cual finalmente necesita y reconoce al final de su artículo cuando dice que un pequeño grupo conducido por Moisés pudo llegar desde allí a Canaán (Na'aman, 2011).

Dicho esto, se puede afirmar que se ha satisfecho en parte el propósito de este trabajo, y es en parte porque las cosas que se pueden afirmar con perfecta seguridad son muy pocas. Es por ello que se tiene que seguir investigando para poder completar los vacíos que las fuentes disponibles en la actualidad no permiten rellenar. Esta investigación debe tener siempre en cuenta los textos bíblicos, eso sí, con las consideraciones necesarias y con una aplicación de la crítica literaria, y permanecer abierta a los avances que pueda realizar cualquier investigador, ya que el fin no es que uno sea el que venda más o menos publicaciones sino que la dinámica que se investiga quede esclarecida.

Se considera, ya para acabar, que el punto donde se debe profundizar más es la relación entre los términos apiru, habiru, shasu y los que hacen referencia a los israelitas o hebreos. Con ello no sólo se avanzará en la temática de la historicidad de los relatos del Éxodo sino también en el origen de la adoración a YHWH y en las características que ésta pudo tener.

\section{Abreviaturas}

Ge. Génesis

Ex. Éxodo

$\mathrm{Nu}$. Números

Deut. Deuteronomio

lo. Josué 
Id. Jueces

2Sa. Segundo libro de Samuel

$2 R e$. Segundo libro de los Reyes

Ps. Salmos

\section{Bibliografía}

Albertz, R. (1999). Historia de la religión de Israel en tiempos del Antiguo Testamento, vol 1. Madrid: Trotta.

Baden, J. S. (2012). From Joseph to Moses: The Narratives of Exodus 1-2. Vetus Testamentum, 62, 133-158.

Bright, J. (1960). A History of Israel. London: SCM Press.

Budde, K. (1899). Die Religion des Volkes Israel bis zur Verbannung. Giessen: J. Ricker Verlagsbuchhandlung.

Day, J. (2000). Yahweh and the Gods and Goddesses of Canaan. Sheffield: Shefieldd Academic Press.

De Vaux, R. (1975). Historia antigua de Israel. Madrid: Cristiandad.

Durand, J. M. (2004-2005). Assyriologie. Annuaire du Collège de France 2004-2005, 563-584.

Finkelstein, I. y Silberman, N. A. (2003). La Biblia desenterrada: Una nueva visión arqueológica del antiguo Israel y de los orígenes de sus textos sagrados. Madrid: Siglo Veintiuno de España Editores.

Galling, K. (ed.) (1968). Texte zur Geschichte Israels. Tübingen: Mohr Siebeck.

Giveon, R. (1971). Les bédouins shosou des documents égyptiens. Leiden: Brill.

Carbajosa, I., González, J. y Varo, F. (2013). La Biblia en su entorno. Estella: Editorial Verbo Divino.

Görg, M. (1978). Ausweisung oder Befreiung? Neue Perspektiven zum sogenannten Exodus. Kairos, 20, 272-280.

Lemche, N. P. (1985). Early Israel: Anthropological and Historical Studies on the Israelite Society Before the Monarchy. Leiden: E. J. Brill.

Liverani, M. (2005). Más Allá de la Biblia. Historia Antigua de Israel. Barcelona: Crítica.

Loretz, O (1984). Habiru-Hebräer. Eine sozio-linguistische Studie über die Herkunft des Gentiliziums 'ibri vom Appellativum habiru. Berlin/Nueva York: De Gruyter.

Na'aman, N. (1984). Habiru and Hebrews: The Transfer of a Social Term to the Literary Sphere. Journal of Near Eastern Studies, 45 (4), 271-288.

Na'aman, N. (2011).The Exodus Story: Between Historical Memory and Historiographical Composition. Journal of Ancient Near Eastern Religions, 11, 39-69.

Noth, M. (1950). Geschichte Israels. Göttingen Theaterstr. 13 : Vandenhoeck \& Ruprecht.

Provan, I., Long, V. y Longman, T. (2003). A Biblical History of Israel. Louisville, KY: Westminster, John Knox Press.

Sacchi, P. (2004). Historia del judaísmo en la época del Segundo Templo: Israel entre los siglos VI a. C. $y / d$. C. Madrid: Trotta.

Soggin, J. A. (1985). A History of Israel: From the Beginnings to the Bar Kochba Revolt, AD 135. London: SCM Press.

Thompson, T. L. (1974). The Historicity of the Patriarchal Narratives: The Quest for the Historical Abraham. Berlin: Walter de Gruyter.

Trebolle, J. (2008) Imagen y palabra de un silencio: la Biblia en su mundo. Madrid: Trotta.

Van Seters, J. (1975). Abraham in History and Tradition. New Haven: Yale University Press.

Weinfeld, M. (1984). Kuntillet 'Ajrud Inscriptions and Their Significance. Studi Epigrafici e Linguistici sul Vicino Oriente antico, 1, 121-130.

Wright, G. E. (2002). Arqueología Bíblica. Madrid: Cristiandad. 


\section{Panta Rei}

PANTA REI es una revista digital de investigación orientada a la Historia y otras ciencias afines. Su principal objetivo es la transmisión del conocimiento científico, dando una oportunidad también a los jóvenes investigadores que quieren abrirse camino en el estudio de las ciencias humanas y sociales. Se compone de estudios originales relacionados con la disciplina histórica así como su didáctica y difusión. Las diferentes secciones que componen la revista son: artículos de investigación, entrevistas a profesionales, recensiones de monografías de actualidad y crónicas de congresos o eventos científicos relevantes.

Todos los artículos publicados son objeto de un proceso de revisión a cargo de un mínimo de dos evaluadores, que se consideran expertos en el ámbito temático del artículo propuesto. Nuestro deseo es poder ofrecer unos contenidos rigurosos, de calidad y de interés.

EI CEPOAT (Centro de Estudios del Próximo Oriente y la Antigüedad Tardía de la Universidad de Murcia) es la institución encargada de la coordinación y gestión de la revista, desde donde anualmente se lanzará la convocatoria para aquellos que estén interesados en publicar sus trabajos, siempre relacionados con la Historia, Arqueología, Historia del Arte, Didáctica de las Ciencias Sociales, etc.

PANTA REI is a digital journal focused on History and other sciences related to it. Its main objective is the transmission of scientific knowledge by giving also an opportunity to young researchers who want to make their way in the study of human and social sciences. It is composed by original studies related to History, as well as its didactics and promotion. The different sections of this journal are: research articles, interviews to professionals, recensions on monographs about current issues and reports about congresses or relevant scientific events.

All the articles published are subject to a revision process carried out by a minimum of two reviewers who are considered to be experts in the field of the article proposed. Our wish is to offer rigorous contents with quality and being of interest to the reader.

CEPOAT (Centre of Studies of the Middle East and Late Antiquity of the University of Murcia) is the institution in charge of the coordination and management of this journal. This is the centre from where the call for papers will be launched for all the people interested in publishing their papers, always related to History, Archeology, Art History, Didactics of the Social Sciences, etc. 


\section{Normas de Publicación}

El autor se compromete a enviar trabajos originales, que no se encuentren publicados en otras revistas ni en otros idiomas. Así mismo, el mismo artículo no podrá ser presentado en otras revistas mientras dure el proceso de evaluación.

\section{Envío y presentación de originales}

Los artículos se enviarán exclusivamente a través del correo electrónico a la dirección pantarei@um.es. Los textos serán enviados en formato DOC y las imágenes en formato JPEG o TIFF, y con un tamaño mínimo de 2000 px. Éstas no aparecerán incorporadas en el texto, sino enviadas en archivo aparte y correctamente numeradas según su posición en el texto. Junto al trabajo, se rellenará y enviará un documento aparte en el que se especifiquen los datos del autor siguiendo el modelo disponible en la página Web de la revista.

Para la redacción de los trabajos se tendrá en cuenta el Manual de la American Psychological Association, en su sexta edición. La extensión máxima de los trabajos será de 30 páginas. La tipografía será Arial 11, con interlineado sencillo y sin espacio alguno entre párrafos. El texto deberá ir justificado a ambos márgenes y sin sangría en los primeros párrafos. Los márgenes serán de $2,50 \mathrm{~cm}$. En los casos en los que fuera necesario incorporar notas, éstas irán a pie de página, enumeradas consecutivamente, con tipografía Arial 10, interlineado sencillo y justificadas a ambos márgenes.

Una información más detallada se encuentra disponible en la página http://www.um.es/cepoat/ pantarei.

\section{Proceso de valoración y evaluación}

Una vez recibidos los trabajos, la Revista realizará una primera valoración. Si el trabajo enviado se ajusta a las normas de presentación propuestas, la temática es coincidente con la línea editorial de la revista y posee la calidad científica necesaria, será remitido al consejo asesor para una primera evaluación. Si no es así en este primer paso se puede rechazar directamente los documentos que incumplan claramente la línea editorial.

Será el Consejo Asesor quien indique a la revista la originalidad, relevancia, estructura, redacción, aparato bibliográfico, etc. del trabajo enviado y, para ello, se designará a dos revisores expertos externos que evaluarán cada uno de los trabajos, que pueden formar parte (o no) de este Consejo Asesor. La selección de los revisores se ajustará a la temática y características metodológicas del trabajo. El nombre y filiación de los autores serán eliminados del trabajo para su revisión, así como los revisores actuarán de manera anónima y confidencial.

Los revisores deberán rellenar un informe de evaluación que centrará su atención en aspectos tales como características formales, originalidad y novedad de los trabajos, relevancia de las propuestas y los resultados, calidad metodológica y validez científica.

Una vez terminado el proceso se decidirá la aceptación o no de los mismos y su publicación en el número que sea pertinente, así como las modificaciones susceptibles de ser realizadas para su final publicación. Dicha notificación se enviará únicamente por correo electrónico, en un plazo máximo de seis meses. 


\section{Publishing rules}

The author is committed to submit original papers not having been published in other reviews or in other languages. In this way, it is not allowed for the same paper to be presented in other reviews during the evaluation process.

\section{Submission and presentation of originals}

The articles will be exclusively submitted by email to pantarei@um.es. The texts will be submitted in DOC format and the images in JPEG or TIFF format, and with a minimum size of 2000 px. Images will not be integrated in the text but sent in another file and properly numbered according to their position in the text. Attached to the paper, a document will be filled out and sent where the author's data will be specified following the model available on the website.

The sixth edition of the Manual of the American Psychological Association will be taken into account for the writing of the papers. The length of the papers must not exceed 30 pages. Typography will be Arial 11 , with simple line spacing and no space between paragraphs. The text must be justified on both margins without indentation in the first paragraphs. Margins size will be $2.50 \mathrm{~cm}$. Where it could be necessary the incorporation of notes, they will be at the bottom of the page, consecutively numbered with typography Arial 10, simple line spacing and justified on both margins.

More detailed information is available on the website: http://www.um.es/cepoat/pantarei.

\section{Examination and assessment process}

The Journal will submit the papers to a first examination once received. If the paper follows the presentation guidelines, the subject agrees with the editorial line of this journal, and possess the scientific quality required, it will be sent to the advisory council for a first assessment. If not, the documents which clearly fail to complete the editorial line may be rejected straightaway in this first step.

The Advisory Council will indicate the originality, relevance, structure, writing, bibliography, etc. of the text to the journal; for this purpose, two outside experts will be designated to review the papers; these experts can be (or not) part of this Advisory Council. The selection of the experts will adjust to the subject and methodological characteristics of the paper. Name and affiliation of the author will be eliminated from the text for its review, in this way experts will act anonymously and confidentially.

The experts will fill out an assessment report which will focus on aspects such as formal characteristics, originality and novelty of the papers, relevance and results of the proposal, methodological quality and scientific validity.

Once the process is finished, the acceptance or not of the papers and its publication in the corresponding edition will be decided, as well as the modifications that may be done for its final publication. This notification will be sent by email within 6 months maximum. 



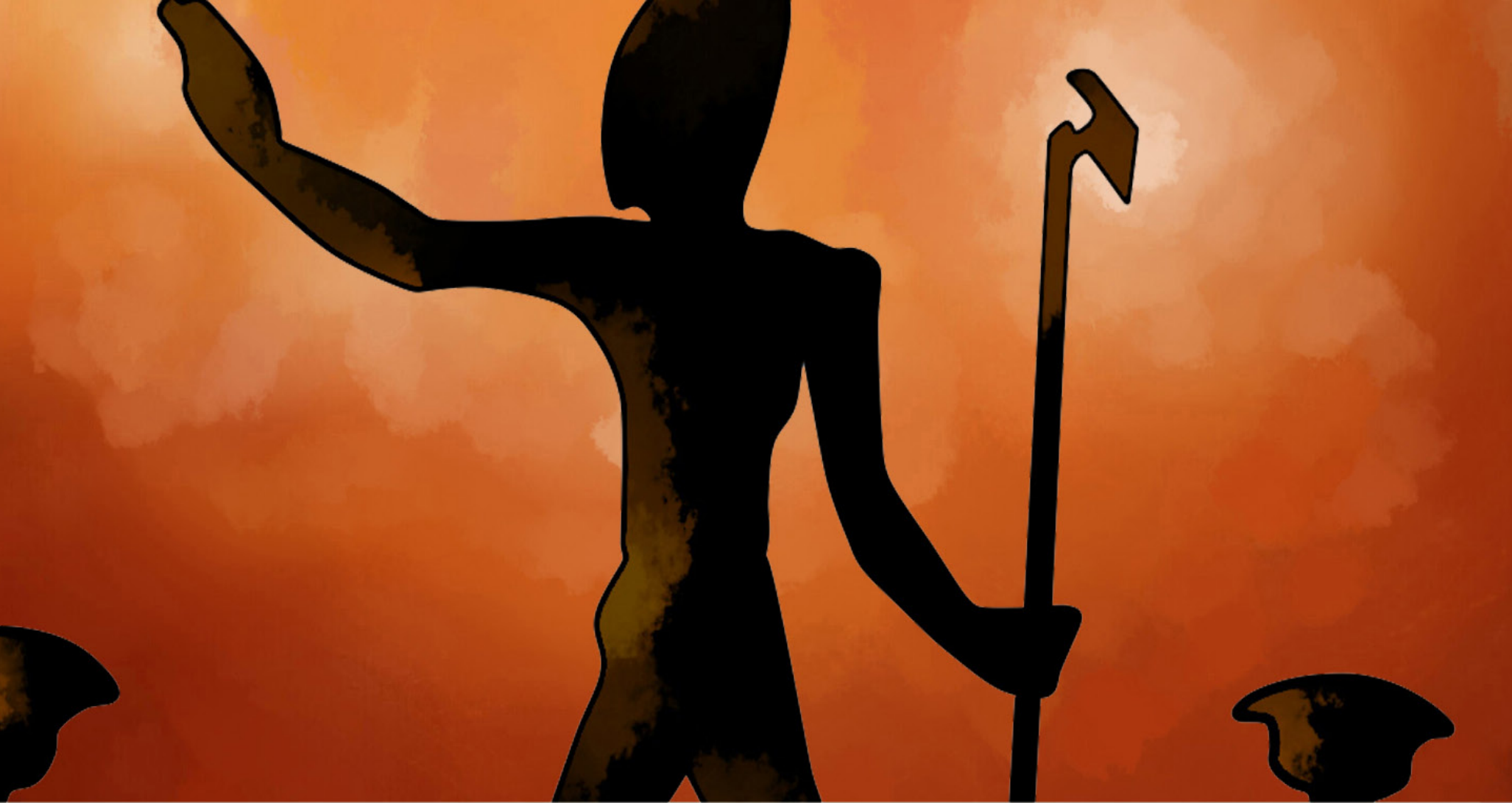

\section{cepoAt}

UNIVERSIDAD DE MURCIA

centro de estudios del

próximo oriente y la

antigüedad tardía 